\title{
LIVING ARRANGEMENTS OF THE ELDERLY IN THAILAND: VIEWS OF THE POPULACE
}

\begin{abstract}
Qualitative data collected in Thailand through a series of 26 focus groups held separately with elderly individuals and adults with elderly parents provides insights into Thai views on a variety of issues related to the living arrangements of the elderly. These include the benefits and problems associated with coresidence, the choice of the coresident caregiver, mechanisms encouraging co-residence, alternatives to living with children, and the impact of social changes on living arrangements. The normative expectation that adult children should care for and support their elderly parents remains deeply ingrained in Thai culture and includes a strong sense of obligation to have at least one child coreside with or live in close proximity to elderly parents is clearly borne out in the focus group discussions.
\end{abstract}

Key Words: Thailand, living arrangements, cultural values, intergenerational relations, focus groups, elderly

In Thailand, as in most Asian countries, the primary responsibility for the elderly has traditionally been with the family. Most observers believe it is in the government's as well as the future elderly's interest to preserve this system. Only recently, however, have systematic attempts been made to examine and assess actual arrangements for support. As a result, quantitative documentation of the current baseline situation is just beginning to accumulate, and systematic qualitative research into the views and opinions of the elderly and their family members themselves is virtually non-existent. ${ }^{1}$ Such qualitative data are essential for gaining insights into the meaning of the quantitative results that are starting to emerge from analyses of surveys and censuses.

In this study, we examine the views of the elderly and their adult children in Thailand relating to living arrangements. Under present conditions at least, coresidence with adult children, or living nearby in functionally related households, is likely to meet the wide range of the Thai elderly's needs more fully than any other aspect of the familial support system. Our analysis is based primarily on qualitative data generated through a series of 26 focus group discussions involving 7 to 9 persons each held in Bangkok and in rural villages in each of the four major regions of Thailand. The fieldwork was conducted by the Institute of Population Studies, Chulalongkom University, during a one-year period spanning 1990-91. Groups were formed based on generation, region, and socio-economic status (SES). The generational distinction refers to elderly (defined as persons age 60 and over) and adult children of elderly (i.e., adults who had at least one living parent aged 60 or over). The regional distinction also serves as an urban-rural distinction as all groups outside of Bangkok were held in rural 
areas. The SES distinction differentiates high and low SES in rural areas and slum dwellers and middle class in Bangkok ${ }^{2}$. In all groups both men and women were represented.

While the focus group transcripts constitute the primary material on which this study is based, we also draw on our knowledge from prior research bearing on the subject of living arrangements for the elderly, both quantitative and qualitative, to help us interpret the transcripts and supplement the focus group findings. The rather subjective nature of focus group analysis often requires dealing with contradictions and "reading between the lines". For this purpose, external material can be helpful. Of particular relevance are the results of an earlier national survey of elderly (and to a lesser extent a companion survey of adults) conducted in 1986 by the Institute of Population Studies as part of a project entitled Socioeconomic Consequences of the Aging Population in Thailand (SECAPT).

The focus group discussions provide insights into how the Thai populace views a variety of issues related to the living arrangements of the elderly such as the benefits and problems associated with co-residence, the choice of the co-resident caregiver, mechanisms encouraging co-residence, alternatives to living with children, and the impact of social changes on living arrangements. In the following presentation of results, we include a number of direct quotations from the focus groups to illustrate our findings. Implied words are included in parentheses when necessary to improve intelligibility. In addition, we sometimes extract comments from a longer discussion for the sake of brevity provided leaving out the intervening statements does not alter the contextual meaning of the quotations presented. Following each quotation, we identify the session from which it comes.

\section{PREFERRED AND ACTUAL LIVING ARRANGEMENTS}

The focus group discussions make clear that the most commonly preferred living arrangement for the elderly is to be with adult children and that this usually implies literal co-residence. This is the predominant view expressed both by the elderly themselves and the adult children, who speak of it as both the elderly's preference as well as their own preference for their parents. In almost all groups, at least some participants explicitly cited co-residence in the same house as the preferred living arrangement of the elderly, and in more than half of the focus groups, there was virtual consensus about this point. Groups with a consensus came from the entire spectrum of groups included in the study design: Bangkok and rural groups in every region, higher and lower SES groups, elderly and adult children groups.

Mr. Kaew: We are old. If we don't stay with our children, with whom can we stay? They have to take care of us as we have done for them.

[North, elderly, high SES]

Moderator: Do you want to be in the same house with your children or next to theirs? 
Ms. Kai: I want to be in the same house with them.

Mr. Rumpoeng: Living separately is difficult. If we eat together, it is easier to understand each other. We can depend on them in various ways. Mr. Pui: If we live separately, they go to work early, not seeing us.

Mr. Tune: If we are together (in the same house), we have a chance to talk to each other. If not, each goes his way, minding his own business.

[Central region, elderly, low SES]

When other preferences were mentioned, almost always the alternative was to live nearby, usually next door or in the same compound or a functionally related cluster of houses. This appears to be the predominant preference in only 4 of the 22 rural groups but in half of the 8 Bangkok groups (middle class, elderly low SES elderly, middle class elderly, low SES elderly, middle class adult children, and low SES adult children), which may signify a genuine rural-urban difference with respect to such views. In most cases in rural areas, it appears that when participants express a preference for separate dwellings, they are referring to households still related by at least limited sharing of some functions such as meal preparation, child care, and care while ill. Even in the Bangkok groups, close relations between the households are often implied.

$M r$. Bunsong: If we live by ourselves, our children should live nearby ... We don't want to live in the same house as our children and grandchildren. It's very noisy and hectic...

Living near our children gives us a warm feeling.

Ms. Jua: I prefer to live in a different house but close to theirs.

Ms. Rumpung: For me, I want to live in a small house surrounded by my children's houses.

[Bangkok, elderly, slum \#1]

As the elderly pass through the old-age span, the composition of the household is likely to evolve, with children leaving the household as they reach ages at which important life course transitions are made (Foster 1975). Single children may move to find work outside of the home community, children who marry may move out to form their own household, and others may return to the parental household after a stint away. Generally, the goal of the elderly is to have one child remain as the designated caregiver, but this final stem family arrangement often does not emerge until the elderly are at more advanced ages. Many parents begin their elderly years with several children coresident. Over time, however, children move out until only one is typically left. Once this child marries and has children, a stem family structure results with the elderly parents, a married adult child, child-in-law, and the grandchildren living together. This pattern is reflected in the SECAPT survey results indicating that over $90 \%$ of co-resident elderly whose children have all married live with only one of their adult children.

$M r$, Loar: If there are many children, each goes to live separately but one of them must remain with the parents. It could be anyone. Usually the youngest daughter stays. However, if there is only one child, parents have no choice.

[Central, elderly, pretest] 
Mr. Paitoon: Either with many or few (children), there must be one left to care for parents... With only 2 of them, one will move out and have his own family and one lives with the parents.

[Northeast, adult children, high SES]

Another general feature of living arrangement preferences that surfaces in a number of the discussions is the fact that Thai elderly typically remain in their own house rather than moving out to live in the house of a child, and many elderly seem to have a strong attachment to their own home. It is unlikely that the elderly are often forced to make a choice between remaining in their own house, living apart from children, or living with an adult child but in the child's home. Nevertheless, the apparent preference for remaining in one's own house may influence how the particular child who eventually remains with the elderly parents is chosen. The choice of the eventual caregiver narrows as older children marry and move out or leave the home area to work and live elsewhere.

Mr. Peng: Usually, the elderly must be with the youngest since the youngest is still in their house. However displeased they feel with him, they have to stay in their own house. Even though the eldest is good to them, they can't live with him since the house that the eldest lives in belongs to the eldest and not to the parents. That is why they love the youngest the best.... The elderly parents don't have the right to make any changes in their children's houses or in the houses of in-laws. The elderly constructed their own house so it's theirs and they have to live in it.

[Central region, adult children, low SES] Mr. Thanom: If it's the children's house, there might be problems and we have to be thoughtful of them. But if it's our house and children are with us, we'll feel better.

[Bangkok, elderly, middle class \#2]

Results from the companion survey of adults in the reproductive ages are consistent with the preferences expressed by the adult children focus groups, with $96 \%$ indicating that in general elderly should live with children. In addition, $87 \%$ of the respondents in the adult survey said that they expect to live with a child when they are elderly themselves. ${ }^{3}$

Results on living arrangements from the SECAPT survey of elderly, the 1990 census, and a 1990 quasi-national survey consistently show that living with children is the most common form of living arrangement for the elderly, with $77-78 \%$ coresiding in the same household (Knodel and Debavalya 1992). Moreover, when allowance is made for cases in which elderly and children live in separate dwelling units but are nearby enough to be in daily contact (i.e., the functional equivalence of co-residence), the figure approaches $90 \%$ (Knodel, Chayovan and Siriboon 1992a). Thus the actual situation conforms fairly closely to the preferences expressed.

An interesting aspect of living arrangements that appears in at least a few cases to be a variant of co-residence is the practice of having the elderly care for 
grandchildren while their parents (the adult children of the elderly) reside elsewhere. This arrangement typically occurs when the adult child has left the rural village to work in Bangkok or some other urban area and has the grandparents bring up the grandchildren back in the home village. However, there are many variations of this pattern, and it need not preclude the elderly being coresident with another adult child. In addition, the arrangement may be only for certain periods of the year. This phenomenon was acknowledged in the vast majority of focus groups. In most cases where grandparents care for the grandchildren, the absent parents pay all or part of the expenses involved, often sending remittances on a regular basis. Whether this service is viewed as a burden to the elderly seems quite variable.

\section{REASONS FOR LIVING WITH CHILDREN}

Undoubtedly the primary consideration for co-residence is that it is seen as the best means through which support and care for the elderly can be assured within the normatively mandated system of familial responsibility for old people, especially during the later years of old age, when the elderly are least able to fend for themselves. The elderly make clear that they need children to depend on, particularly when they are sick. They believe they are due such care as repayment for having raised their children. This view is shared by their children, who feel a moral obligation to support and care for their parents out of gratitude. Nevertheless, other considerations are also at play. In most cases, co-residence (or living in close proximity) involves an exchange of services and material support flowing in both directions, with costs and benefits to each generation.

While the following discussion concentrates on co-residence as a moral obligation and on its pragmatic value, a more affective aspect is often also involved in motivating children and parents to live together. Some adult children stated that living with elderly parents gave them a feeling of warmth, security, or completeness.

Mr. Sumroey: We feel warm and secure having (elderly parents) with us. I'm very proud just seeing them at home even though they can't do anything in return.

Ms. Charlerm: We feel happy and encouraged to see them there when we return from the field.

Mr. Noi: Yes, with old people at home, the house is complete and full.

[Central, adult children, pretest]

\section{Co-Residence as a Moral Obligation}

The focus group discussions indicate that adult children's sense of moral obligation to take care of elderly parents is a pervasive aspect of Thai cultural values and provides a strong normative basis for the prevailing pattern of living arrangements. Participants across the whole spectrum of groups spontaneously mentioned that parents deserve to be taken care of in their old age by the chil- 
dren as a form of repayment. This belief is shared by both generations and is found in all regions, transcending economic status or rural-urban residence.

Repaying parents is viewed as a continual obligation that starts when the children are old enough to provide meaningful help and typically begins long before parents reach old age. Thus young adult children whose parents are still middle aged would also be expected to contribute to their parents' welfare out of this same sense of debt. However, the care and support provided by children when their parents are too old to take care of themselves is viewed as the culmination of this process.

Mr. Jai: Children have to take care of their parents who brought them up... They must not forget parents' meritorious acts ...

[Central, elderly, high SES]

Mr. Pui: Parents are supreme since they gave birth to us. We have to take care of them until death do us part.

[Central, elderly, low SES] Mr. Khummee: We raised them. If we can't work anymore, it is their duty to care for us.

Mr. Chanha: Since we have children, we live with them... They have to care for us since we are their parents and brought them up. They must grateful...

[Northeast, elderly, high SES: $117,159,179]^{\wedge}$

Mr. Triam: Parents cared for children since they were babies so the children must care for parents in return...

[Northeast, adult children, Low SES]

Underlying the obligation to repay parents are the concepts of "katanyu katawethi' and 'bunkun,' both of which are firmly ingrained in Thai culture but have no simple English equivalents (Rabibhadana 1984; Podhisita 1985). Both terms relate to reciprocation of favors which incur a sense of gratitude and debt. Katanyu refers to a constant sense of awareness on the part of someone for benefits which another person has bestowed upon him. Katawethi refers to doing something in return for them. Bunkun characterizes the person who bestows favors which instill a sense of gratitude and debt in the beneficiary.

The concept of katanyu katawethi usually refers specifically to parent-child relationships while bunkun extends to many realms of life. Both concepts, however, characterize the essence of the relationship between parents and children and were used by participants in the focus group discussions. Giving life to and raising a child provides parents with the epitome of bunkun and instills a sense of gratitude and debt in the child that is virtually impossible to repay completely. This bunkun parents have in relation to children directly leads to the sense of obligation adult children have to provide support and care to them when the parents are in their elderly years.

\section{Co-Residence as Mutual Assistance}

Interdependence between generations is another influence underlying the prevailing preference for living together. Clearly the net direction of the flow of ser- 
vices and supports between parents and children will depend on the life course stages of both. Initially, children are entirely dependent on parents, but over time parents become increasingly dependent on children and particularly those who are co-resident. Parents' physical strength, mental agility, and overall health typically decline with age while at the same time their children become adults and increasingly capable of contributing to keeping up the household and assisting their parents. In a very general sense, the concept of parent repayment recognizes this sequential life course shift in interdependencies.

A different type of interdependence underlying co-residence (or living in close proximity) involves ongoing mutual assistance in maintaining the household. Clearly the typical situation of co-residence involves a two-way flow in assistance between generations. Adult children are often primarily responsible for economic activities although meaningful contributions are still made by the elderly. Elderly parents usually share household chores and child care responsibilities with their children. Children are also expected to be available to care for the elderly when they are ill and in times of emergencies.

Ms. Tui: Early in the morning at daybreak, the children cook for us, then they go to the rice field. Things we can't do like carrying water, they do for us and make us comfortable. (Laughed) Sometimes when they are out of the house, we prepare the meal for them in the evening.

Ms. Somnuk: They are tired from working. We are at home. We do the things we can do. What we can't, they do for themselves. We depend on each other.

Mr. Chote: We have them to look after us. We depend on each other... The house belongs to us. If we don't let them live with us, they can't do anything. (Laughed)

Ms. Somnuk: Our children have to go to work. So we have to look after the grandchildren. Otherwise, they can't go to work. It has to be like that.

[Central, elderly, high SES]

The balance of services and other forms of assistance exchanged between elderly parents and co-resident adult children (as well as those living elsewhere) varies with the particular circumstances of each family and is undoubtedly conditioned by the life course stage of both generations. Some of the same functions performed by elderly parents for adult children at one stage, such as cooking or house cleaning, are at a later stage performed by the children. Other benefits, however, flow only in a particular direction between generations when parents are elderly.

\section{Benefits of Co-Residence for the Elderly}

Health care concerns appear to be the area of need of the elderly most salient to focus group participants. This includes help getting to a doctor or hospital, help in paying medical bills, and personal care when ill or bed-ridden. Care during both temporary and chronic illness are mentioned. The need to have someone present to notice and help in case of emergency is a paramount concern. Several 
elderly people mentioned that if they lived alone, they could become ill without anyone noticing before they died.

Ms. Charoon: Yes, we would like to be close to the children in case that we are taken ill. How can we ask somebody else to take us to the hospital...

Moderator: What do old people want children to do for them since you say that they must be with their children?

Mr. Loem: Help when they are sick; do everything.

Ms. Charoon: (Children) will care for them in every way. Some are sick stay in bed all the time. Children have to clean their urine and feces.

[Central, adult children, high SES]

Moderator: Do old couples want to be with children or to be together by themselves?

Ms. Boonthom and Mr. Kaeoma: Oh! To be with children.

Ms. Lamai: No one is to care for you when you are ill if you are together by yourselves...

Ms. Bang and Ms. Khumsuk: To be in the same house so they can call their children to help when they are ill during the night.

[North, adult children, high SES]

Many elderly also expect to receive help from children in attending to their normal daily needs such as food preparation, doing laundry, etc. Among these chores, preparing food seems to be the most common service provided by children. Generally elderly want to contribute to such chores as much as they comfortably can to reduce children's burden and maintain some self-sufficiency. Indeed the theme of wishing to do things for themselves often came up in the discussions. But if the elderly are no longer able to help in household chores then they expect the children to take full responsibility.

\section{Benefits of Co-Residence for Adult Children}

Only rarely was it stated explicitly that a main reason for living with children was to assist the children. Nevertheless, in virtually every focus group, whether of the elderly or the adult children, participants indicated that elderly parents contributed a variety of services to the household. These included helping with child care, doing household chores such as cleaning and cooking, and guarding the house when other adults were not present.

Child care was probably the most frequently mentioned service that elderly co-resident parents provide their adult children although household chores were also mentioned in almost all groups. The fact that adult children typically work outside the home creates a need for child care for their young children. Elderly parents, who are often not active in economic activities or limit their economic activities to things that can be done at home are particularly suitable for taking care of grandchildren. Occasionally elderly participants complained about being burdened by child care responsibilities, but often they accepted this role as natural and necessary. 
Ms. Boonthom:...We feel secure having [elderly parents] with us. Moreover, when we are out to work, there is someone home to look after the house and our children... If we have grandparents with us, we can leave our children all day long and go to work since both are cared by them.

[North, adult children, high]

Mr. Poend: My children are still my responsibility since I still have to care for their children.

[Bangkok, elderly, middle class]

The elderly help with a variety of household chores such as sweeping and cleaning, caring for the yard, guarding the house, and tending the pigs. Generally the main tasks that they do not do are ones that require great physical strength. Of particular value to children is the assistance elderly provide with meal preparation. It is apparent that in some cases the elderly have the primary responsibility for doing the cooking. Some participants mentioned that elderly are not used to modern appliances such as electric rice cookers or gas stoves and that this handicaps their ability to make meals. The general impression from the focus groups, however, is that for many households this is a real service for the other members and part of a pragmatic division of labor that facilitates the work of adult children outside the house. While some elderly complained, the general impression given is that they want to avoid feeling useless and are more than willing to contribute to the household functions. Indeed, adult children sometimes complained they wanted their elderly parents to take it easy and do less but were unable to prevent their parents from being so active.

Ms. Boonsri: (Elderly) cook food, wash up, care for grandchildren, clean house, cut grass and other things if children are not free to do them ... They do it themselves ... They don't want to stay doing nothing.

[South, adult children, high SES]

Ms. Durian: Children go out to work but we stay at home. So we should prepare food for them so when they came back very tired they can have it right away.

Ms. Nom: We can't stand not doing it. We have to do it.

Ms. Durian: If we don't, they are hungry and get angry since they have to spend time to prepare it themselves.

[Central, elderly, low SES]

Another important contribution that the elderly make to co-resident children is the use of the premises as a domicile, given that it typically is the elderly's own house in which the children are living. Likewise, the co-resident children have access to the productive resources such as farm machinery or other equipment that the elderly may have accumulated. In some cases, the elderly also contribute economically to the upkeep of the household through sharing income that they receive in the form of earnings or remittances. Finally, as discussed below, the child that ultimately remains with the parents in rural areas is usually entitled to use the parents' share of land and eventually receives it as an extra part of his or 
her inheritance. Because these rules are somewhat implicit, they were not directly mentioned by the participants as such when asked how the elderly contribute. Nevertheless, contributions of this nature are potentially of great importance.

\section{CHOICE OF THE CO-RESIDENT CAREGIVER}

Although numerous adult children spend some time co-residing with elderly parents, the final household structure that evolves by the last years of the parents' lives typically involves a stem family with only one married adult child together with that child's spouse and children (Foster 1975). The determination of which child eventually stays with the parents undoubtedly involves a process with numerous variations. From the focus group discussions, the choice appears to be influenced by both normative considerations regarding gender and birth order as well as practical and emotional considerations. Daughters and youngest children are most commonly favored, but there is considerable flexibility whenever circumstances warrant it.

\section{Gender and Birth Order}

In the large majority of focus group sessions, participants specifically indicate that elderly prefer to live with a daughter rather than a son. A preference to live with the youngest child is also mentioned frequently although usually qualified by indicating it should be the youngest daughter. Nevertheless, it was evident in many of the discussions that other considerations besides gender and birth order are important and that the rules were flexible. In only a minority of the sessions did it appear that preference for a daughter and particularly the youngest daughter, was paramount above other considerations such as dependability, willingness, and compatibility.

Moderator: Usually with whom do old people want to be?

Mr. Boonthum: Most of them are with the youngest daughter... They are in original family house with the youngest child... If there are no daughters, it's necessary for them to be with a son.

[North, adult children, high SES]

Mr. Tune: Traditionally Thais prefer to be with the youngest daughter... It is the custom. We follow the traditional custom.

[Central, elderly, low SES]

Moderator: Do old parents prefer to be with sons or daughters?

Mr. Pramote: Most prefer daughters...

Mr. Somchai: Daughters are closer. They take better care of parents.

Ms. Boonpas: There is also (the issue of) daughters-in-law. They are good to parents-in-law in front of husbands, but if the husband is not there they may not be so helpful.

[South, adult children, low SES]

A number of reasons were given why there is a general preference to live with daughters and youngest children. One reason is that this is the traditional choice. 
But the discussions also brought out the rationale behind the tradition as well as the fact that practical considerations can override it. Daughters are typically perceived to be emotionally closer to parents, more dependable, and better caregivers. There is clear recognition that sons and daughters are socialized into different roles and that the role of daughters in Thai society is better suited for providing personal care to parents than is the role of sons. Sons are also expected to help support parents but by contributing through economic activities rather than helping in the household and attending to the personal needs of the elderly.

Focus group participants in every region and in Bangkok mentioned that daughters are better caregivers than sons. Also, in all regions except the central, spontaneous comments were made to the effect that daughters are emotionally closer to parents than were sons. While a co-resident married son would have a wife who could fulfill functions consistent with the female role, there is a common feeling that one's own daughter is better suited for providing more intimate types of care than a daughter-in-law.

Thais also commonly perceive that there is less potential for friction with a son-in-law than with a daughter-in-law. This likely stems from the more central role that a younger generation female plays in the household in terms of chores compared to a younger generation male. As elderly typically spend most of their time at home, there is greater potential for disagreements over a range of daily activities between a daughter-in-law and co-resident elderly than between a son-in-law and co-resident elderly. This may also reflect a perception that males are less emotional than women and thus less likely to get offended over small matters in the household.

Moderator: Do sons-in-law usually disagree with parents-in-law?

Mr. Boonthum: Hardly.

Ms. Lamai: Only a few cases since men are hardly home. They are ones who earn the income so they are not with parents-in-law all the time. They go out to work early in the moming. However, daughters-in-law are home with mothers-in-law.

[North, adult children, high SES]

Difficulties of co-residing with a child-in-law, especially a daughter-in-law, came up spontaneously in a number of focus groups. Explicit examples were provided indicating that co-residence with a particular child was avoided due to a problem with or aversion to the child's spouse. In several cases, avoiding inlaw friction was even stated as the reason for living separately from children (although presumably still in close proximity to them).

The preference for the youngest child or daughter to be the permanent co-resident child is at least in part an outcome of the sequential process through which children leave the household to marry or work elsewhere. Although temporary post-nuptial co-residence with one of the couple's parents (usually the wife's) is common in most cases, it usually lasts for only a few years, after which the couple moves to a house of their own (Limanonda 1989). Thus typically the youngest will be the last child left in the household after elder siblings move out and thus 
has little choice but to remain permanently with the aging parents. Beyond this, however, some participants suggest that parents usually feel closest to the youngest child. This feeling could in part result from the expectation that the youngest will be the final caregiver for the parents.

Ms. Pim: Most prefer to be with the youngest. They tend to love the youngest the best.

Mr. Peng: The youngest is the last and is with old people when they are quite old. So they think that one will always be with them to care for them, not anybody else. The youngest will massage them when they have strained muscles. So they tend to love him most...

Mr. Samarn: Usually, the elder ones marry and move out.

Mr. Peng: Yes. The youngest tends to be with them so they hope to depend to him. Others have all moved out but the old people remain at their (own) home close by.

[Central, adult children, low SES]

Mr. Choen: Older children tend to marry first and move out. The youngest tends to marry last and still be with parents. That's why we tend to be with the youngest.

[South, elderly, high SES]

Quantitative data from the SECAPT survey are quite consistent with the impressions gained from the focus groups. Elderly are more likely to live with a daughter than a son, particularly when married children are considered and especially in the northeast and north. Nevertheless, substantial minorities tend to live with sons, and elderly with only sons are as likely to co-reside with a son as those with only daughters are to coreside with a daughter. This pattern clearly testifies to the ability to be flexible when circumstances limit options (Knodel, Chayovan and Siriboon 1992a).

\section{Other Considerations}

While gender and birth order preferences were commonly expressed, rarely did they seem to be the paramount consideration. More important to the elderly is that the co-resident child be dependable, compatible, and/or close to the parents emotionally. In addition, the child should be willing to co-reside and be sufficiently grateful to make the situation comfortable for both parties. Daughters are considered more likely to fit this description, but if they do not, co-residence can be with a son. The adult children expressed similar views about the criteria that will be important when they decide with whom to spend their old age.

Moderator: If there are many children, how can you decide with whom to stay?

Mr. Nuan: The one that is good, we are with that one... The grateful one who doesn't forget parents.

[Northeast, elderly. low SES] Ms. Chunya: I think (elderly) want to be with the one they love... (If there are) many children, they will choose the one they love most. 
Moderator: Is he the youngest or the eldest?

Ms. Chunya: They won't consider this point if they are happy with him.

[Bangkok, adult children, middle class group \#1]

The financial status of the child may also play a role, but elderly do not necessarily prefer to live with children who are better off. In some groups, on the contrary, elderly choose to co-reside with the child most in need of help. In part, this is likely to be related to whether the parents move to the child's house or the child stays in the parents' house, thereby benefiting from the parent's resources. Moreover, some elderly may want to feel useful rather than being a burden to their co-resident child.

Mr. Peng: To be honest, parents prefer being with children who are poor to being with the rich ones... They pity them and want to help in any way they can such as caring for grandchildren while the parents are out to work.

[Central, adult children, low SES]

Ms. Somsri: Most old people choose to be with poor children, not with the rich ones...

Mr. Sawing: They are worried about the poor one since those rich children are fine enough.

[Bangkok, adult children, slum site \#1]

\section{MECHANISMS ENCOURAGING CO-RESIDENCE}

Co-residence with children has been identified in the anthropological literature as the traditional living arrangement of the elderly. The present high levels of co-residence (e.g., $76 \%$ and $77 \%$ of women age 60 and above according to the 1980 and 1990 national censuses respectively) persist despite the substantial social and economic change that has been taking place in Thailand. In general, two major means operate in virtually all societies to maintain familial-based systems of support and care for the elderly: 1) cultural norms of filial piety combined with reciprocal affection and goodwill leading to parents investing in children and children repaying parents through assistance in old age; and 2) mechanisms of control designed to ensure that the normatively mandated obligations will be met. With reference to this second category, the most strategic instrument elderly household heads typically have which can be used to punish non-cooperative behavior on the part of their children is control over inheritance (Nydegger 1983; Nugent 1990). Thailand is no exception in this respect.

As previously discussed, strong cultural values pervade Thai society prescribing moral obligations on children to support and care for their elderly parents as a form of repayment. These norms appear to be internalized by most Thais but also reinforced by other members of the family and community. In the focus groups, participants were asked directly how parents can help ensure that they will receive support and care from their adult children. Some participants stress that there is no way to be certain of support. Almost all groups, however, mentioned the importance of retaining property to serve as an incentive for at least 
one child to remain with their parents to the end. Also frequently mentioned was the importance of properly socializing children with respect to the sense of gratitude and moral obligation that underlies the process of parent repayment. Finally, some participants mentioned that the elderly themselves need to be agreeable and reasonable if they expect children to continue to coreside.

\section{Retention of Property}

Although substantial growth in the non-agricultural sector is transforming the nature of the economy, Thailand has been and still is a predominantly agrarian society. Thus traditionally, agricultural land has been the most important possession of most families and the most important part of inheritance. Despite increasing landlessness in recent decades, in most areas of Thailand farmers still own their own land. When parents reach old age and children marry and form families of their own, the parents often allocate the land among the children through a verbal declaration but without necessarily formally ceding ownership. In some cases legal transfer may be made later to avoid conflicts among children after the parents die. In either event, a portion is typically retained by the parents for their own use. The child that remains co-resident will often farm both the parents' share and his or her own share, with the produce going to the household. The customary inheritance practice is for both sons and daughters to receive equal shares with the qualification that the child who remains with and cares for the elderly parents inherits the house and two shares of land, the one allocated originally and the one that was retained by the parents.

This practice was mentioned in almost all rural groups and even in most Bangkok groups, although in the latter sometimes property other than land was cited. It is clearly considered to be an important mechanism through which parents can guarantee that one of their children will look after them until the end as well as give the parents a back up if the children do not. Postponing the transfer of ownership of the shares of land that parents distribute to children before death is also seen as a means of leverage to ensure the non-coresident children's continued concern for the parents.

Mr. Paitoon: Property is not all divided to the children. Some is, but a part is kept by the parents...

Ms. Bunkwang: Yes, that part is a guarantee... Whoever cares for them until they die gets that part to make merit (for the parents).

[Northeast, adult children, high SES] Mr. Chompoo... If rice-fields are to be distributed, a part must be kept by the parents ... When the parents die, this part will belong to the one who cares for the parents... It's like a payment for what he does... It's a normal practice in every family or else no-one would care for old people (Laughed).

[North, adult children, high SES]

Mr.Choen: The central part (of the land) is kept just in case of emergency... 
Ms. Prachoeb: Yes. If parents are deserted, they are sure to have a means to maintain themselves.

Mr. Choen:... they keep it as a custom... Whoever cares for parents will get it.

[South, elderly, high SES]

Although participants can very clearly articulate the rationale behind the practice of parents keeping a part of the land for themselves, the practice is best seen as a custom rather than the product of individual predictions that particular children will be unfilial. This interpretation is underscored by the fact that the practice is linked to proverbs. All four groups in the north and one in the northeast referred to the proverb indicating that parents without property are like a log without mushrooms.

Mr. Kaew: (There is a old proverb:) "A log that has no mushrooms is left as uncut timber lying on the ground"... (A log) without mushrooms refers to old people who have no property...

[North, elderly, high SES]

In addition, all four southern groups and one Bangkok group called the share retained by elderly parents the 'spirit' property, referring to the parent's share insuring that sufficient collateral will be available to fund appropriate merit making activities on their behalf after death. This association came up in groups in other regions as well even though the term 'spirit' property was not used.

Mr. Pramote: Most (elderly) keep a piece of land which is called 'a spirit piece'. Whoever takes care of the parents will get it ... Just a part, not all. Most do it that way. (It's the) part kept for the spirit.

[South, adult children, low SES]

Mr. Singh:... Whoever gets the (parents') share must make good merit on behalf of the dead parents.

[Northeast, elderly, low SES]

In a certain sense, the many statements that children have a strong moral obligation to care for parents in their old age would seem to contradict the almost equally common view that property is needed to guarantee such care. This apparent contradiction can be resolved by viewing both the moral responsibility of parent repayment and the practice of retaining property as an incentive/guarantee as part of the same normative system that functions to promote familial support. The latter undoubtedly developed as a way to reinforce the former. Moreover, pragmatism is a noted feature of Thai society (Mole 1973: 83-84). Thus, in a matter so crucial as care and support in old age, the less left to chance the better.

In reality, parents without much property are also cared for within the context of a co-residential living arrangement. This fact is evident from the SECAPT survey data and is recognized by a number of participants in the focus groups. According to the SECAPT surveys, $72 \%$ of elderly who said they had no property or wealth to give children are co-resident with a child, $79 \%$ of those who had property or wealth but distributed all or some of it were co-resident, 
and $77 \%$ of elderly who have still retained their property and wealth were co-resident. Even rural landless laborers, however, often own at least a house and a small yard, which can serve as an incentive to the co-resident caregiver. Moreover, in many cases, material rewards are probably not necessary as internalized feelings of gratitude and duty reinforced by normative pressure are enough to ensure that elderly parents are not left on their own (Nugent 1990).

Moderator: Comparing parents who keep some rice-fields for themselves and ones who don't, who are cared for better?

Ms. Lamai: Whether they keep some or not, we care for them.

Mr. Boonthum: If they don't have rice-fields to share, we still care for them ... We were born poor people so we care for the parents according to our financial state. We have to face the situation. Since they don't have anything to give us, we can't force them with guns to have it.

[North, adult children, high SES]

While co-residence occurs regardless of whether there is a substantial legacy of property to act as an incentive, the extent and quality of care provided may be affected. Although participants in a number of focus groups suggest this, it is difficult to confirm with existing survey data. Whether or not it is true, it seems clear that the normative expectation that adult children be responsible for their elderly parents' welfare and that at least one live with the parents is sufficient to make the system of familial care work even where material incentives are few.

\section{Proper Socialization}

Besides retaining property, participants believe that proper socialization concerning the obligation to care for parents later in life is an important way to increase the chances of adequate care when parents are elderly. Specific reference was often made to the concepts of katanyu katawethi and bunkun in the focus groups. Proper socialization can be achieved in various ways such as by appropriate upbringing by the parents themselves, suitable teaching by others, and the setting of good examples.

Moderator: Is there a way, like keeping a property, to guarantee that children will care for parents?

Ms. Lorm: First of all, you have to train the children to be good persons ... I trained mine with the idea that they will care for me for the rest of my life.

[South, elderly, low SES]

Ms. Toam: We have to give them examples by doing it ourselves such as to support older relatives... We have to support our parents. If not, children will take it for granted that they don't have to.

[Bangkok, elderly, slum \#2]

The sense of gratitude and obligation is reinforced by community disapproval of children who shirk their responsibilities with regard to the normatively mandated support and care for elderly parents. Although comments to this effect did not arise spontaneously, this point is implicit in much of the discussion about the appropriate role of children as caregivers. 


\section{Proper Attitude and Behaviour}

Participants in several groups stressed that elderly parents needed to behave in a manner that would encourage adult children to stay with them. Elderly should not be too fussy, place too much of a burden on children, or interfere with the adult children's private lives, and should be agreeable and not constantly complain or criticize. Otherwise the children may seek out a place of their own. Children also need to maintain the appropriate attitude or risk having the parents stay with another child or eschew co-residence altogether.

Ms. Samuth: My husband said that I was very fussy, children might not want to care for me. He himself tries to behave since he is afraid of being deserted by the children.

[Central, adult children, high SES]

\section{STRAINS OF CO-RESIDENCE}

The focus groups make clear that co-residence is not without strains. Complaints about problems stemming from living together were heard from both the elderly and the adult children. Generally, however, the strains were expressed from the point of view of the elderly. Adult children rarely criticized co-residence from their own standpoint, perhaps being reluctant to appear to contradict the normatively mandated moral obligation. In many cases, problems mentioned regarding co-residence seemed to reflect rather specific individual circumstances or personalities. Nevertheless, several patterns emerge which suggest the strains result from more general cultural values not totally compatible with a stem family household structure. The most common strains mentioned involve lack of privacy and conflict between parents and children-in-law. These strains or the anticipation of them led to some elderly parents residing in separate dwellings, but others tolerated them to varying degrees.

One advantage of a strong sense of moral obligation underlying the prevailing pattern of living arrangements is that it smooths the relationship between the elderly parents and co-residential children. This sense helps children to be more understanding of their parents and tolerate what they judge to be unpleasant behavior.

Ms. Bang: We are annoyed with fussy parents but we just leave the house when they complain. We come back when we no longer feel angry. What can we do since they are our own mothers.

Ms. Bunloe: Without them, you can't be born... We must show gratitude to them, give them whatever they want to eat.

[North, adult children, low SES]

For many families economic advantages to co-residence also promote toleration of the associated difficulties arising from intergenerational living arrangements. Some participants at least viewed their options as to where and with whom to live as severely limited. Only under extreme circumstances will strains of co-residence lead one of the parties to change their residence. 


\section{In-law Conflict}

While friction between elderly parents and the spouse of the co-resident child is not universal, it is common, being spontaneously mentioned in most groups. Relations with daughters-in-law were perceived to be more problematic than those with sons-in-law and sometimes led to long discussions. Many exceptions were noted, however, both personal examples of harmonious relations and occasional mention that sons-in-law sometimes are more problematic than daughters-inlaw. Still it is clear that in-law conflict is an inherent source of strain within the preferred stem family household structure.

Ms. Lek: Daughters-in-law are good to parents-in-law only when husbands are there. If not, they threaten to poison them. (Laughed)

[South, elderly, low SES]

Mr. Boonthum: If daughters-in-law and mothers-in-law are together, it's either a log or a hammer. That's a northern saying. (It means) whatever they can snatch, they will use it to hit each other.

[North, adult children, high SES]

The strain seems to stem in part from the fact that the Thai value system stresses primary allegiance of each adult child to his/her own parents and thus the in-law will often be perceived as less devoted than the co-resident elderly's own child. The focus groups reveal common views of daughters-in law in the context of co-residence as less dependable than one's own children, less under the elderly's control, and less considerate than one's own child. Quite probably, since children-in-law were not brought up by the co-resident elderly parents themselves, they are nor seen as having the same moral obligation to serve the parents-in-law as they would their own parents. Another season the childin-law may be perceived as the source of strain is that the house in which he or she co-resids typically belongs to the elder and the child-in-law is in some sense intruding.

Ms. Pan: In-laws are not the same as children. We don't know them as we do our children since our children were brought up by ourselves.

[Central, adult children, low SES]

Ms. Nom: A daughter-in-law can't be compared to our own daughters. We can scold (our daughters) since they are ours.

Mr. Tune: It's hard to get along with a daughter-in-law. She is an outsider...

Mr. Pui: If we do something that displeases her, she will complain. If she does something wrong, we can't complain. If they are our children, we can.

[Central, elderly, low SES]

Another area where cultural values may increase the chance of conflict with daughters-in-law is in the gender patterning of control of household money. Traditional Thai values assign the wife responsibility for household finances. Adult children's strong obligation to help their own parents may lead a co-resident daughter-in-law to send household money to her own parents. This action is 
probably more difficult for a co-resident son-in-law to do because he does not control the finances.

Mr. Bunsong: It can't be ensured to get some money from our children. Our son may want to give us some but his wife objects to this. He can't give us that money.

Ms. Ruan: A wife can put aside some of the money that a husband gives to her for her parents. The wife won't tell her husband about this. She'll say that all the money is gone. When the husband asks for some money from her to give it to his parents, she'll tell him that there's none left.

Moderator: In a family who keeps money?

Ms. Ruan: The wife, so we can ask for some from our daughter but not from our son.

[Bangkok, elderly, Slum 1]

\section{Lack of Privacy}

Discussions of why some elderly prefer to live in separate dwelling units commonly involve issues of their need for some privacy, peace and quiet, absence of interference in their desired lifestyle, and lack of involvement in arguments of the younger generation couple. This desire for privacy leads some elderly to live separately from adult children but generally not far away. Living apart, especially in rural settings, usually takes the form of simply living next to or near adult children. The noise and activities of grandchildren as well as arguments among adult children and particularly among spouses were commonly cited as irritants to the elderly and sources of discomfort. In some cases, these disturbances resulted in an elderly parent preferring a separate dwelling, even if this meant compromising the extent of help and services received.

Ms. Tumma: I want (my children) to support me but I don't want to be in the same house ... But they must support us. In that case, it's alright since it's like being in the same family. Only that we live in our house... We feel more at ease that way. No one bothers us... We are by ourselves. They prepare us meals ... but they do not interfere much with us ...

Mr. Chanha: Let me explain. We want peace. In the big house, when many people gather to drink, it's very noisy. We don't like it since we want to live quietly. I don't like a noisy atmosphere.

[Northeast, elderly, high SES]

\section{ALTERNATIVES TO LIVING WITH OR NEAR CHILDREN}

In Thailand, where co-residence with an adult child is the norm, childless elderly or those whose children do not live with or near them are of particular interest. In such cases, the focus group participants make clear that the responsibility should remain within the family. If at all possible, other relatives should take over the caregiver role. As a last resort, some participants indicate that deserted 
and destitute elderly can turn to the temple although this is seen as a rare event. The concept of old age homes is not very familiar and is generally viewed negatively. Cases in which elderly are forced to rely on institutional care are seen as a reflection of the failure of the family to fulfill their obligation and thus cast shame on those who normally would take responsibility.

\section{Relatives}

Participants frequently mentioned that other family members, particularly siblings and nieces or nephews, should be responsible in cases where either the elderly have no children or the children have deserted their parents. In most discussions, however, it was not clear whether the provision of care necessarily involved co-residence with these relatives. The SECAPT survey results indicate that only one third of childless elderly live alone or with their spouse only and almost half $(48 \%)$ live with an economically active or adult younger generation relative, typically a niece or nephew (Siriboon and Knodel forthcoming).

Ms. Pim: If (old people) don't have children, they will have brothers and sisters who have children. They expect to depend on one of them ... If we can't depend on relatives, on whom can we depend?

[Central, adult children, low SES]

Many groups implied that old people who are without the help of children will be looked after to some extent by members of the community, especially neighbors. Such help, however, obviously does not include co-residence in the literal sense and probably implies some form of back-up assistance rather than full-scale care.

\section{Institutional Living}

As a last resort, a number of participants mentioned that elderly could turn to the temple for help and even go to live there in some extreme cases, although this is rare. While temples are not specifically set up to provide charity in Thailand, leftover food from the monks can be shared among destitute elderly. Some participants specifically denied that they have ever seen or heard of elderly going to live in the temple. Others made it clear that if elderly individuals are forced by circumstances to rely on the temple for support, it would reflect very badly on the children and relatives and thus is limited to a rare few who are without kin or any other means of support.

Mr. Win: In my opinion, (if I had no children) I would depend on the help of a temple but I'm not sure I'll be taken there. (Laughed)... If you have no one, you must aim to depend on a temple... Just pay respect to an abbot and ask to be taken in... He will give us the leftover food offered to him. A temple is the best place if without children, grandchildren or nieces and nephews.

[South, elderly, high SES]

Ms. Somkid: If children let parents (live in a temple), they will be blamed by villagers and be ashamed. 
Mr. Bunloe: If there's no choice, they have to depend on a temple.

[North, adult children, low SES]

Living in special institutional residences for the aged, including nursing homes is also very rare in Thailand. At present the government sponsors only about a dozen such homes housing, only a few thousand elderly, and private institutional residences are also few. The government homes are not nursing homes as such, although some limited nursing services are provided. Rather they function more as residences for elderly who are not especially medically hand capped but who are unable or unwilling to live alone or with children or relatives. The first model home for the elderly established four decades ago has been featured a number of times on television. As a result, perceptions about old folks' homes among the public, to the extent that they are aware of such institutions at all, are heavily influenced by their impression of this particular home.

When focus group participants were asked upon whom old people without children could hope to depend, homes for the aged were rarely mentioned spontaneously by rural participants but came up more commonly in the Bangkok groups. Reactions of both elderly and adult children participants to the idea of an elderly person being sent to an old folks' home were usually negative. Only in cases where there were no children or relatives to care for an elderly person was the idea of institutional care generally seen as acceptable. These negative attitudes stem from the deeply held view that care for the elderly in Thai culture is the responsibility of family members. Residing in an old age home, or even in a nursing home in the case of a chronically ill elderly person, is seen as a failure of the family support system and worthy of social disapproval.

Ms. Kunya: However poor I am, I won't let my parents be (in an old folks home). If the government wants to help them other ways, it's okay.

Ms. Boonsri: It's as if we minded having them with us when they were too old to do anything... It looks like we reject our responsibility.

[South, adult children, high SES]

Ms. Pattra: We heard about (old folks homes) but have never considered it (as a possibility).

Ms. Thanorm: It's for those who do not have relatives and need help. Those who have children, grandchildren or nieces and nephews won't have problems like that.

Ms. Pattra: I won't let my parents be there if I'm still alive, no matter [how] poor I am.

[Bangkok, adult children, middle class, group]

The typical discussion combined statements accepting the idea of institutional care for elderly people who had no alternatives with comments that the participants themselves are unwilling to be (or let their parents be) in an old folks' home. Insufficient and incorrect information also contributes to negative views of nursing homes. A fairly common impression is that such homes are only for those elderly with money. Also, participants believed that residents in these 
homes lacked freedom of movement and thus equated them with prisons. In two groups of adult children, however, some sentiment was expressed that institutional homes for the elderly might be advantageous for urban elderly in the future if children no longer feel obligated to care for parents.

\section{SOCIAL CHANGES INFLUENCING LIVING ARRANGEMENTS}

The focus group discussions provide clear qualitative evidence that a strong tradition persists of the elderly being supported and cared for by the family and that at the center of this familial support system is the practice of living with children. Quantitative data indicate that this form of living arrangement is still very pervasive despite the substantial social and economic change that has engulfed Thai society during recent decades. Most significantly, comparisons of the percentage of elderly women living with children remained virtually constant between 1980 and 1990 according to the national censuses (estimates for men are not available from the censuses - see Knodel, Chayovan, and Saengtienchai forthcoming.) Nevertheless, there is no guarantee that the major social changes taking place will not have some impact on both the form and extent of support that families will provide the elderly in coming decades. Of interest in the present study is the extent to which the current pattern of living arrangements is likely to persist and what social forces are likely to shape the future course.

The literature on current and future trends in support for the elderly in Third World settings and in Asia in particular has both asserted and speculated that rapid social and economic changes are having or will soon have profound effects on the circumstances of the future elderly. The changes most commonly cited include the following: declines in the number of children couples have; increased involvement of women (the predominant caretakers) in economic activities outside the home; physical separation of parents and adult children associated with urbanization and age-selective rural to urban work-related migration; and ideational change, especially the spread of western style individualism through mass media and public education (Mason 1991; Martin 1989, 1990; Caldwell 1982). In the focus group discussions, we attempted to probe the views of participants concerning whether and how the familial support system is changing and what the future situation is likely to be.

\section{Perceived Trends in Living Arrangements}

The elderly groups were asked to compare the present situation with that of a generation or so in the past. In most elderly groups, when the moderator asked about differences between the present and preceding generations, little explicit discussion about changes in living arrangements arose. In only two groups did participants suggest that co-residence is on the decline and in one that children were less likely to live in households next to the parents. In several others, the participants seemed to feel that there was little change in co-residence. Given that co-residence is still high among the current generation of elderly it is not 
surprising that little mention was made of any major changes in living arrangements by elderly participants.

The adult children groups were asked a different question, namely if they thought the care they would receive when they were elderly would differ from that given to the elderly at present. The discussion on the future of family care for the elderly by the adult child groups showed considerable consensus. Most groups believe that the care they would receive from their own children would be less than what the current generation of elderly receives and that co-residence was likely to decline. These changes in the familial support system were seen as the likely outcome of a set of related social changes involving increased education, changing occupations, and work-related migration. These changes generally increase the chance that the next generation of elderly will live separately from adult children and perhaps not even in the same vicinity.

Moderator: Do you think when you are old that your children will care for you as you did for your parents?

$M r$ Sin: There will certainly be problems ...

Mr. Sumroey: They belong to the new generation... I don't expect any of my children to care for me. (Laughed)

Ms. Sanun: Have to depend on ourselves first.

Mr. Sin: They just go away to continue their studies.

$M r$. Peng: Then, they go to work somewhere away from home.

[Central, adult children, low SES]

Moderator: Then do you think you are to be given the same kind of support as you are giving to your parents?

Mr. Kane: We are to have less support. People tend to go away from home to earn a living. There are many who have already left ...

Ms. Bunkwang: Parents will have a more difficult time since children will not be with them.

[Northeast, adult children, high SES]

Although a fear of living in later life without the company of a co-resident child was commonly expressed by the adult children groups, there was not a clear consensus that the future elderly will live apart from their children. A number of those who spoke appear not to believe this. They saw the obligation of children to repay parents by caring for them in their old age as so firmly ingrained in Thai culture that they could not anticipate change in foreseeable future. In their view, co-residence will continue to be practiced as long as children have a sense of gratitude.

Moderator: When people of your generation in this village become old, do you think they will depend on their children the same way as their parents depend on them?

Mr. Noi: They may not be with us, but they will send us things and money. Since they have to work elsewhere, they can't be with us or cook for us. 
Mr. Thawat: If they know the mother is by herself, they'll have the mother move to be with them.

[Central, adult children, pretest] Mr. Prasobe:... There will be a child who cares for the parents ... even in the future.

Unidentified $(M)$ : There must be. Old people won't be deserted... There must be one in the family.

Mr. Prasobe: There must be some good ones. They can't be all bad.

[Northeast, adult children, low SES]

\section{Declining Family Size}

When asked about the likely effect on old age support of the current trend to have small families, participants gave different answers. Some, by no means the majority, agreed that having a large number of children is beneficial in insuring parental support in old age. The negative effects of small family size for the support and care of parents were often qualified by indicating that couples can no longer afford to bring up large families. Nevertheless some participants saw having larger families as increasing the change that at least one child will be dependable, allowing parents to have more choice with whom to live, and allowing children to share some of the responsibilities of care.

$M r$ Thongdee: With fewer children, it's harder to find some to care for parents.

[Northeast, adult children, high SES]

Ms. Choen: With many children it has to be good. With only one, you have no choice. Whether he is good or not, you have to be with him.

Ms. Perm: When bringing them up and they are young, one is an ideal number. (Laughed) However, with a lot of grown up children, parents feel more comfortable.

[Bangkok, elderly, middle class, group \#2]

The large majority of groups, however, felt that having small families does not in itself seriously jeopardize support, including the crucial aspect of co-residence, during the elderly years. This view predominated across the full spectrum of groups as defined by generation, region (including Bangkok and rural groups), and socio-economic status. The centrality of a stem family household arrangement whereby only one child is the primary caregiver undoubtedly influences the perceptions of many participants with respect to the effect of reduced family size. Thus numerous participants pointed out that even with many children, only one eventually cares for the elderly parents.

Ms. Kai: If one child is willing to care for us, we are as well cared for as if many of them do for us ... With many not all care for us. It's good enough to have one of them care for parents all the time.

[Northeast, elderly, high SES]

Mr. Paitoon: With many or few (children) there must be one left to care for parents... With only two, one will move out and have his own 
family and one will stay with the parents.

[Northeast, adult children, high SES]

Probably the most common reason given for believing that having fewer children will not necessarily be disadvantageous for care and support in old age is the belief that the character and behaviour of children are what count and not the number.

Mr. Boontha: Some have a lot of children but no one is with them. Some have two children and both of them take care of parents.

[North, adult children, high SES]

Ms. Choen: Whether they are a few or many doesn't matter. If they are good, they will care for the parents. Those few children will still care for them.

[Bangkok, elderly, middle class, group \#2]

Mr. Wichit: If he is good child, 1 is enough.

Mr. Aroone: Yes.

Mr. Wichit: If they are all bad, 10 are useless.

[Bangkok, Elderly, Slum \#2]

Interestingly, participants who stressed character do not seem to feel that having more children increases the chance that one or more will have the desirable traits. This view may in part stem from a conviction that few children can be raised better than many and thus, with only a few, parents can better instill the sense of gratitude that leads to taking care of parents later in life. Several ways were mentioned that small families can be beneficial when parents are elderly. Having fewer children permits greater investment in their education, which in turn can improve their ability to provide for parents. Moreover, parents with small families are in a better position to save for their old age. Several participants also implied that responsibility for parents is more clearly defined with only a few children. In large families it is easier for any particular child to "pass the buck" risking the chance that no one takes on the responsibility.

Moderator: Who is going to look after parent day parents assuming they have only two children?

Ms. Loem: They work and save some money for themselves since there are only two (children) to be provided for. . They work to educate the children to save some money. When they are old, the children care for them ... Mr. Loar: With a few children, parents can provide them with good education. If there are many of them, they can't.

[Central, elderly, pretest]

Mr. Pui: Just one good child is enough to care for parents ...

Ms. Durian: Sometimes, with many of them, no one agrees to care for parents. They say it's another one's responsibility.

[Central, elderly, low SES]

Results from the SECAPT survey provide some relevant information on the impact of family size on living arrangements (Knodel, Chayovan, and Siriboon, $1992 \mathrm{~b}$ ). Among the current generation of elderly parents, there is only relatively 
weak association between chances of co-residing with a child and number of living children. For example, elderly with two living children are only modestly less likely to co-reside with a child $(71 \%)$ than those larger families $(82 \%)$. Even the majority of elderly $(62 \%)$ who have only one child are co-resident with that child.

\section{Work Related Migration}

The most important social change affecting the familial system of support for elderly in the minds of the focus group participants appears to be increasing workrelated migration stimulated by the changing Thai economy and increasing levels of education of recent labor force entrants. This phenomenon involves migration to urban areas to take jobs in the expanding modern sector or in the informal service sector as well as migration to other rural areas, often on a temporary basis, to meet the seasonal needs of commercial agriculture, which has also expanded substantially. Another form of migration that has emerged over the last decade or two involves labor contracts to work abroad, particularly in the Middle East. In this case, migration is also temporary but often lasts for several years.

Much of the work-related migration involves adult children whose elderly parents remain in the village, although in most cases one of the migrant's siblings also remains. Moreover, urban-to-urban migration is also stimulated by economic modernization although, in the case of Thailand, it is probably far less important in separating adult children from their elderly parents since the urban population is so heavily concentrated in just one city (Bangkok). Although temporary and long term migration are by no means new phenomena in Thailand, participants of both generations perceive that it is increased substantially over recent decades and that this pattern has implications for support and living arrangements of the elderly, particularly those in rural areas.

Mr. Tune: In the former times, (parents and children) lived as a closeknit family. Nowadays, they are scattering in all provinces, Bangkok, Korat, and elsewhere. Wherever they can earn a good living, they will go afar.

[Central, elderly, low SES]

Mr. Muk: Children nowadays earn a living in Bangkok. I followed (mine) there and asked them to come back. But they didn't come back. They have been there one year. They don't want to come back... They're afraid if they came back and would have to work (in the rice fields), their hands would turn back. They didn't want to do it. There they have to rent a house, and buy rice. But they earn money everyday. Mr. Pow: When they are asked to work on rice fields, they shake their heads.

[North, elderly, high SES]

As noted above, work-related migration is seen as already affecting living arrangements, as it underlies the emerging phenomenon of grandchildren living in the household of the elderly grandparents whose own adult children have migrated elsewhere to find work. While increased migration of working aged 
adults may have affected the extent to which elderly are surrounded by 'satellite households' of adult children, the quantitative data cited above indicate that it has yet to seriously erode co-residence. In a sense, the focus group discussions are consistent with this fact in that participants mention that many children leave the village but rarely cite cases where elderly have been totally deserted. Among adult children, however, there is considerable concern that work-related migration will undermine co-residence when they become elderly. As noted above, not all agree. Some see the norm for living with children being sufficiently ingrained that at least one child will remain behind, while others do not.

Moderator: Do you think that when your generation is 70 or 80 your children will care for you better than you (now) care for your own parents? Ms. Samuth: If (they don't), they will feel ashamed.

Mr. Loem: I don't think they will feel ashamed.

Ms. Prapai: They might live very far away from us ...

Mr. Loeam: They will be away from us, go to work somewhere far away.

[Central, adult children, high SES]

Mr. Kane: We are to have less support (in the future). People tend to go away from home to earn their living...

Ms. Noolom: Most children nowadays hardly stay home when they finished the school...

Ms. Sa-iem: They go to Bangkok to earn their living.

Ms. Bungwang: Parents will have more difficult lives (in the future) since children will not be with them.

[Northeast, adult children, high SES]

The expansion of formal education is closely linked to work-related migration in the minds of many focus group participants, particularly in the rural areas. Most adult children of today's elderly have been educated only to the primary level, but most participants recognize that secondary education is spreading rapidly among younger cohorts, who will be the adult children of elderly parents in the future. They also recognize that education may affect the occupational preferences of children and that appropriate job opportunities for better educated persons lie outside of agriculture in government service and the modern sector and thus require migration away from the home area. Indeed, children may leave in the course of receiving an education since schools beyond the secondary level are largely concentrated too far from most villages to permit commuting.

Mr. Peng: With two children, we can support them to any kind of education they want to do. So they all go far away to work as soldiers or policemen. We two, the parents, are left by ourselves. They can't have us with them since they are always on the move.

[Central, adult children, low SES] Ms. Charoon:... The more educated they are, the better kind of job they seek.

Ms. Prapai: The father asks the child to stay home but he says no, saying that if he would like to stay at home, he would not have studied. (Laughed)

[Central, adult children, high SES] 
Children living away from home, however, is not seen as all bad. In virtually every focus group, participants recognized that absent children often send remittances or at least occasional financial contributions. The ideal for many elderly is likely to be a combination of co-residence with a child who remains behind and remittances from a child who migrates elsewhere.

$M s$. Ubol: In case of money matters it must be those who are away from them since those who live with them feed them regularly.

[Bangkok, adult children, slum \#1]

Mr. Suchart: Children who are with parents may not have money to spend on them when they are taken ill. Those who are not with parents may be able to provide the sum. They have different advantages.

[Bangkok, adult children, middle class group \#2]

\section{Changing Type of Work Within Home Communities}

While economic change has stimulated long distance migration, especially to urban centers, factories are also being set up in rural areas and providing new opportunities for work. This increase in non-agricultural work in rural areas has an impact on both the ability of adult children to care for co-resident elderly and the need for the elderly to take care of the household and the grandchildren. In particular, rural factories often require some amount of commuting and may keep the adult children away from the home and at a further distance than traditional agricultural pursuits did. In some cases, the workers may stay in dormitories at the factory site and come back home only on days off.

Although the literature on the elderly in developing countries often singles out women's increasing employment outside the home as a threat to the existing familial support systems, this issue virtually never arose among focus group participants. It is probably true that in Thailand a disproportionate share of care for elderly parents is done by younger generation women and indeed this in part underlies the preference for living with a daughter. Nevertheless, with respect to co-residence, the problem of daughters working outside the home as creating a particular problem was rarely mentioned. Traditionally, in rural areas, husbands and wives work together in the fields, and, thus, competition for a woman's time between economic activities and caring for elderly is not new.

\section{Ideational and Lifestyles Changes}

The lifestyle led by Thais both in rural and in urban areas is changing rapidly under the impact of economic development, spreading consumerism, and changes in the nature and type of work that people do. These changes are particularly evident in Bangkok, where traffic congestion and the rapid expansion of the metropolis contribute to increasing time and effort being spent getting back and forth to work. In one of the middle class elderly groups in Bangkok, participants mentioned that the lifestyle imposed on their children by living and working in Bangkok detracts considerably from the quality of interaction between the generations within the household. However, there was little indication that this problem resulted in a decrease in co-residence. In some respects the 
fact that adult children are out of the house most of the day and are exhausted when they return could increase the value of having parents co-resident.

Moderator: I wonder whether old people want children to do things like cooking rice, washing clothes and other routine chores for them.

Ms. Perm: They don't have time to do it for us since they go to work in the morning and come back very late.

Ms. Thongchan: They hardly do anything. We ourselves have to prepare food for them. (Laughed)

[Bangkok, elderly, middle class, group \#2]

$M r$ Tub: All my children go out to work in the morning and I'm on my own at home... When they are with me, I hardly have a chance to chat with them. Early in the morning, after taking a shower, they just go out... (They come back) as late as $8-9$ p.m. and I'm sleepy by that time... Moreover, there is a traffic jam. So, in a month, we may have only one chance to talk to each other. They're too tired whenever they are home.

[Bangkok, elderly, middle class, group \#2]

Although the concept of filial responsibility for parents' welfare later in life is firmly ingrained in the traditional Thai value system, this value has been reinforced by the predominance of family farming as the major economic activity and the dependence of children on inheriting land, controlled by parents. As the cconomic base of Thai society shifts away from family subsistence farming and towards wage labor and the non-agricultural sector, the parents' economic leverage over their children weakens. Moreover, exposure to Western ideas regarding the family, in which emphasis on filial responsibility is considerably less, as well as the spread of materialistic values could potentially contribute to changing views held by adult children regarding their obligations towards their parents. This change in turn could influence living arrangements.

The prospect of ideational change eroding children's commitment to their parents arose occasionally in the focus groups, especially in connection with assessments of whether children will care for the next generation of elderly. There was little indication, however, that the level of commitment at present was reduced.

Mr. Pramote: Children can't be close to parents since they are more knowledgeable, more educated. There is more technological progress so old people are useless to have around. So they may leave them at a home for elderly.

Mr. Win: Some of this generation's children still love parents but those of the next generation will not love them enough to care for them.

[South, adult children, low SES]

Ms. Chum: Many of the educated children leave parents.

Ms. Toam: They think they are better than the parents.

Ms. Chun: They leave parents to care for their wives and children.

[Bangkok, elderly, slum \#2] 
Although the above quotations implicate increasing formal education as contributing to a declining sense of filial piety, this was not a common view. More typically, increasing education was seen as creating a problem for co-residence because it led to jobs away from the home areas, especially for rural village parents, not that it undermined a sense of filial responsibility. Indeed, many participants explicitly denied this. Rather they indicated that instead of co-residence, educated children could provide financial support through regular remittances or occasional gifts.

\section{Government Policy and Programs}

Living arrangements can also be influenced by government policies and programs, especially those aimed towards the elderly. At present, few would directly decrease dependence of elderly on the family. Only token government institutional facilities for housing are available for the elderly and plans for expanding such facilities are limited. While pensions could increase financial independence of elderly and thereby encourage more separate living, no extensive public pension system yet exists. Only a small minority of elderly individuals who were government employees or worked in selective private firms receive pensions currently. A social security law has recently been passed which incorporates plans to introduce payments to the elderly in the future. However, details on how it will be implemented have yet to be worked out. Indeed, few focus group participants expect any meaningful financial assistance from the government.

\section{CONCLUSIONS}

The qualitative data generated through focus group discussions mesh well with quantitative data derived from surveys and other sources. The focus groups clarify the strong and pervasive normative underpinning for the prevailing pattem of co-residence of elderly parents with at least one adult child. The sense of moral obligation for children to care for their elderly parents that is instilled from an early age appears deeply rooted in the Thai value system and thus unlikely to vanish in the foreseeable future even under the onslaught of social and economic change. The persistence of high levels of co-residence at present testifies to this.

Nevertheless, Thais are noted for their adaptability to changing circumstances. While the focus group discussions underscore the normative basis of a co-residential living arrangement, they also make clear that there are costs as well as benefits involved for both generations and that the balance of these vary both with the life course stage of the elderly and their children and with the changing external social and economic environment. Thus various modifications of living arrangements may occur in the future. It is possible that substantial outmigration from rural areas in response to changing work opportunities has already started to reduce the extent to which elderly parents in villages are surrounded by functionally related households of non-co-resident children even if the extent of co-residence has not declined. Such a change is not necessarily 
negative in its consequences for the elderly, since children who move away from the home community often provide remittances or material support.

Even if a decline in co-residence occurs, it will not necessarily represent a deterioration of the present situation for the elderly. The current system of coresidence and material support from non-co-resident children, while normatively ingrained in Thai culture, is also in part an economic necessity rooted in the poverty that has traditionally characterized the majority of the population. That co-residence is considered a mixed blessing by many elderly is evident from the focus group discussions. The most common complaints refer to the lack of peace and quiet and to mutual interference when living in close quarters with different generations. To the extent that the substantial economic growth of recent decades persists and translates into increased per capita income for broader segments of the Thai population, future elderly may become more self-supporting. Under such circumstances, it is conceivable that some elderly will deliberately choose to purchase greater privacy in living arrangements with their increased wealth.

\section{NOTES}

1. The first national survey of elderly was undertaken in 1986 (Chayovan, Wongsith, and Saengtienchai 1988). A quasi-national survey was also undertaken in 1990 (Andrews and Hennick 1992). Census and other surveys not specifically targeting elderly have also been analyzed (e.g., Chayovan, Knodel, and Siriboon 1990). Some qualitative work on a local level has also been undertaken (e.g., Caffrey 1992a and 1992b).

2. Opinions of local informants (e.g., the village headman) combined with observations by the research team and information collected during home visits were used to screen participants for higher and lower socio-economic status. Two rural pretest groups (one with elderly and one with adult children) also included in the analysis were not differentiated by SES.

3. More exactly, these percentages refer to living with children, grandchildren, or nieces or nephews as implied by the commonly use Thai term luuklaan. Undoubtedly in most cases the respondents are thinking of the elderly's own children, but it is not possible to distinguish children from grandchildren, nieces, and nephews given their inclusion in the same concept.

\section{REFERENCES}

Andrews, G. and M. Hennink 1992 The Circumstances and Contributions of Older Persons in Three Asian Countries: Preliminary Results of a Cross-national Study. AsiaPacific Population Journal 7(3): 127-146.

Caffrey, R.A. 1992a Family Care of The Elderly in Northeast Thailand: Changing Patterns Journal of Cross-Cultural Gerontology 7(2): 105-116.

Caffrey, R.A. 1992b Caregiving to The Elderly in Northeast Thailand: Changing Patterns, Journal of Cross-cultural Gerontology 7(2): 117-134.

Caldwell, J.C. 1982 The Theory of Fertility Decline. New York: Academic Press.

Chayovan, N., J. Knodel, and S. Siriboon 1990 Thailand's Elderly Population: A Demographic and Social Profile Based on Official Statistical Sources. Comparative Study of the Elderly in Asia, Research Report No. 90-2. Ann Arbor: Population Studies Center, University of Michigan. 
Chayovan, N., M. Wongsith, and C. Saengtienchai 1988 Socio-Economic Consequences of the Ageing of the Population in Thailand: Survey Findings. Bangkok: Institute of Population Studies, Chulalongkom University.

Foster, B. 1975 Continuity and Change in Rural Thai Family Structure. Journal of Anthropological Research 31: 34-50.

Knodel, J., N. Chayovan, and C. Saengtienchai forthcoming Are Thais Deserting Their Elderly Parents? New Evidence from the 1990 Census. Bold 4(3).

Knodel, J., N. Chayovan, and S. Siriboon. 1992a The Familial Support System of Thai Elderly: An Overview. Asia-pacific Population Journal 7(3): 105-126.

Knodel, J., N. Chayovan, and S. Siriboon 1992b The Impact of Fertility Decline on the Familial Support System of the Elderly: An Illustration from Thailand. Population and Development Review 18(1):79-102.

Knodel, J. and N. Debavalya 1992 Social and Economic Support Systems for the Elderly in Asia: An Introduction. Asia-Pacific Population Journal 7(3): 5-12.

Limanonda, B. 1989 Analysis of Postnuptial Residence Patterns of Thai Women. In Institute of Population Studies, Health and Population Studies Based on the 1987 Thailand Demographic and Health Survey. Demographic and Health Surveys Further Analysis Series, No. 1. New York: Population Council and Institute for Resource Development.

Martin, L. 1989 Living Arrangements of the Elderly in Fiji, Korea, Malaysia, and the Philippines. Demography 26: 627-643.

Martin, L. 1990 Changing Intergenerational Family Relations in East Asia. The Annals 510 (July 1990): 102-114.

Mason, K.O. 1991 Family Change and Support of the Elderly in Asia. In United Nations, Population Ageing in Asia. Asian Population Studies Series No. 108. New York: United Nations.

Mole, R.L. 1973 Thai Values and Behavior Patterns. Rutland, Vt.: Charles E. Tuttle.

Nugent, J.B. 1990 Old Age Security and The Defense of Social Norms. Journal of CrossCultural Gerontology 5: 243-254.

Nydegger, C.N. 1983. Family Ties of the Aged in Cross-Cultural Perspective The Gerontologist 23(1): 26-32.

Podhisita, C. 1985 Buddhism and the Thai World View. In Traditional and Changing Thai World View. Amara Pongsapich, et al. pp. 25-53. Bangkok: Social Science Research Institute, Chulalongkorn University.

Rabibhadana, A. 1984 Kinship, Marriage and the Thai Social System. In Perspective on the Thai Marriage, Aphichat Chamratrithirong, ed., IPSR Publication no. $81 \mathrm{Pp} 1-27$. Bangkok: Institute for Population and Social Research, Mahidol University.

Siriboon, S. and J. Knodel. Forthcoming. Thai Elderly Who Do Not Co-reside with Their Children. Journal of Cross-Cultural Gerontology.

\section{Population Studies Center}

University of Michigan

1225 S. University

Ann Arbor, Michigan 48104 - 2590

U.S.A

Institute of Population Studies

Chulalongkorn University

Bangkok, Thailand 
Thai Red Cross Society

Program on AIDS

1871 Rama IV

Bangkok 10330

Thailand 